\title{
Balloon pulmonary angioplasty for the treatment of chronic thromboembolic pulmonary hypertension: is Europe behind?
}

\author{
Irene M. Lang ${ }^{1}$ and Hiromi Matsubara ${ }^{2}$ \\ Affiliations: 'Dept of Internal Medicine II, Division of Cardiology, Vienna General Hospital, Medical University \\ of Vienna, Vienna, Austria. ${ }^{2}$ National Hospital Organization, Okayama Medical Center, Okayama, Japan. \\ Correspondence: Irene M. Lang, Dept of Internal Medicine II, Division of Cardiology, Medical University of \\ Vienna, Währinger Gürtel 18-20, 1090 Vienna, Austria. E-mail: irene.langlameduniwien.ac.at
}

@ERSpublications

The French experience of balloon pulmonary angioplasty for chronic thromboembolic pulmonary hypertension is discussed in the context of international BPA experience http://bit.ly/2H6LamY

Cite this article as: Lang IM, Matsubara H. Balloon pulmonary angioplasty for the treatment of chronic thromboembolic pulmonary hypertension: is Europe behind? Eur Respir J 2019; 53: 1900843 [https://doi.org/10.1183/13993003.00843-2019].

In their French experience of balloon pulmonary angioplasty (BPA) for chronic thromboembolic pulmonary hypertension (CTEPH), BRENOT et al. [1] describe all consecutive patients with inoperable CTEPH who underwent BPA at the French Reference Centre for Pulmonary Hypertension at Université Paris-Sud, France. All cases were discussed in a weekly multidisciplinary meeting including experienced surgeons for pulmonary endarterectomy, interventional radiologists/cardiologists, radiologists experienced in pulmonary vascular imaging and physicians with expertise in pulmonary hypertension, as recommended in the most recent ESC/ERS pulmonary hypertension guidelines [2]. In that setting, 184 patients were deemed eligible for BPA and underwent a total of 1006 BPA sessions. The authors conclude that a refined BPA strategy improves symptoms, exercise capacity and haemodynamics in inoperable CTEPH patients.

This is the largest single-centre BPA experience outside of Japan to this date (the largest from Japan comprises 1408 procedures [3]). One of the other strengths is that it provides a thorough description of the procedure, and state-of-the-art peri-procedural management, for example anticoagulation. What is concerning is that results were worse than in the Japanese multicentre registry, which reported a post-procedural mean pulmonary arterial pressure (mPAP) of $22 \mathrm{mmHg}$, compared with a post-procedural mPAP of $31 \mathrm{mmHg}$ in the present dataset (table 1), while pre-procedural mPAP was $43 \mathrm{mmHg}$ in both datasets. Another Japanese single-centre report concluded the procedures with a post-procedural mPAP of around $20 \mathrm{mmHg}$ [4], corresponding to near-normalisation of resting pressures [5]. In the German dataset that was published in 2017, final post-procedural mPAP was $33 \mathrm{mmHg}$ (table 1) [6]. Other European series provide similar data [7]. Is European (French) CTEPH different? Or did the authors not seek treatment of all segments? Or were they not able to treat all segments? The precise mechanisms of diverging results remain uncertain, but some contributing factors are discussed below.

After a first case report in 1988 [8] and the pivotal report from Feinstein in 2001 [9] with a discouraging $5.6 \%$ death rate, a $61 \%$ incidence of lung injury and a $17 \%$ requirement for mechanical ventilation [9],

This article has been revised according to the correction published in the October 2019 issue of the European Respiratory Journal.

Received: April 282019 | Accepted after revision: May 062019

Copyright OERS 2019 
TABLE 1 European versus Japanese balloon pulmonary angioplasty (BPA)

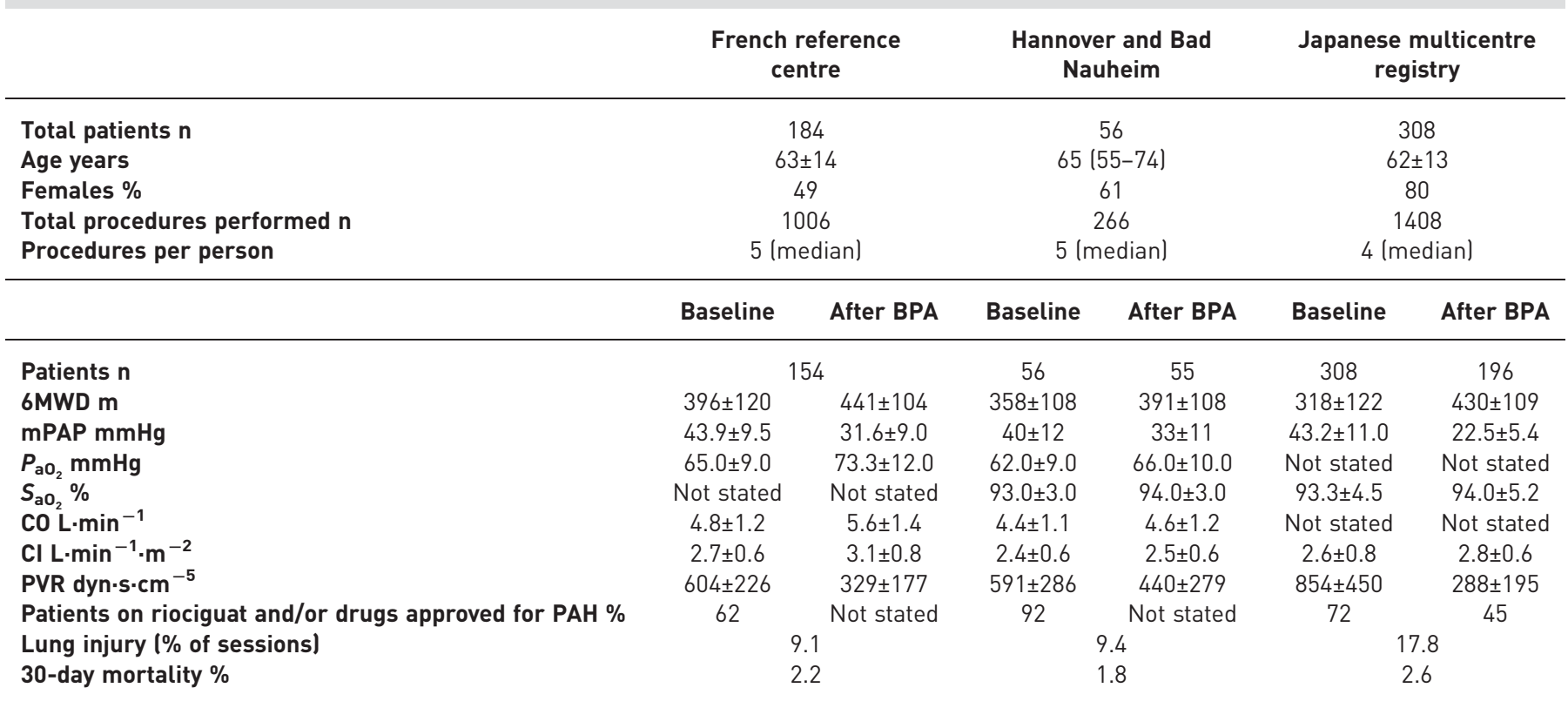

Data are presented as mean \pm SD or median (interquartile range), unless stated otherwise. 6MWD: 6-min walk distance; mPAP: mean pulmonary artery pressure; $P_{\mathrm{aO}_{2}}$ : arterial oxygen tension; $\mathrm{S}_{\mathrm{aO}_{2}}$ : arterial oxygen saturation; $\mathrm{CO}$ : cardiac output; $\mathrm{Cl}$ : cardiac index; PVR: pulmonary vascular resistance; $\mathrm{PAH}$ : pulmonary arterial hypertension.

BPA underwent refinement by Japanese interventionists [10], which set a new standard for the procedure by 2012. While there are currently 1.7 surgical pulmonary endarterectomies per million of population performed in Europe annually, compared with 0.9 per million in the USA, only approximately 60 pulmonary endarterectomies are performed annually in Japan, accounting for 0.47 procedures per million population. While many of the Japanese patients undergoing BPA are considered operable by European surgeons, European BPA patients are classified mainly as technically non-operable, or non-operable due to poor risk benefit ratio. Therefore, patient selection could be a main reason for different BPA outcomes.

While BRENOT et al. [1] conclude that BPA is associated with a high rate of complications, overall BPA risk is low: similar to the daily risk of adverse outcomes in patients undergoing complex coronary lesion revascularisation [11]. One must also bear in mind that pulmonary endarterectomy in high-risk patients confers a 30-day mortality of $>5 \%$ [12]. Learning curves and case loads classically factor in procedural complication rates of percutaneous intervention in general, both in Japan [13] and the USA [14]. Operator experience, together with refinement of BPA technique [10], play key roles in decreasing BPA-related complications. The early US [9] and European [7] experiences reported high peri-procedural death rates. Because of the higher prevalence of venous thromboembolism in the Western World (one per thousand) compared with Japan (28-32 per million inhabitants), a larger case load of CTEPH is to be expected in the future in Europe. Whether a pressure-wire guided technique for monitoring distal perfusion pressure in patients with crossable lesions and baseline $\mathrm{mPAP} \geqslant 45 \mathrm{mmHg}$ [15] confers greater procedural safety remains controversial, and this technique is not currently practised in all major BPA centres of the world.

BRENOT et al. [1] demonstrate that patients with lung injury had significantly higher baseline mPAP (OR $1.08,95 \%$ CI 1.039-1.130; $\mathrm{p}<0.001$ ) and pulmonary vascular resistance, and poorer exercise capacity (as measured by 6-min walk distance) (shown in table 4 of their manuscript). Those factors, and the period during which the BPA procedure was performed (recent versus initial period; OR 0.367 , 95\% CI 0.175 $0.771 ; \mathrm{p}=0.008$ ), were significantly related to lung injury. While the observation that patients with more severe disease have worse outcomes is not surprising, the observation that mPAP carries prognostic information is of interest. Previous data have emphasised the prognostic role of baseline mPAP for CTEPH [16] and pulmonary arterial hypertension [17]. Pulmonary vascular resistance has been the major prognostic haemodynamic measure for CTEPH subjected to pulmonary endarterectomy [18]. By baseline mPAP, the Japanese and European series do not appear significantly different, with $43.2 \pm 11.0 \mathrm{mmHg}$ in the patients studied by Ogawa et al. [3] and around $40 \mathrm{mmHg}$ in those reported by Inami et al. [15], compared with $40 \pm 12 \mathrm{mmHg}$ in the study reported by OLSSON et al. [6] and $43.9 \pm 9.5 \mathrm{mmHg}$ in the French series [1]. However, after a comparable number of sessions (median 4 procedures per patient in the OGAWA et al. [3] 
series, and mean 5-6 procedures per patient in the French series [1], which is more procedures per patient than in the German series [6]) final mPAP was $22.5 \pm 5.4$ as reported by OGAWA et al. [3] and $31.6 \pm 9.0 \mathrm{mmHg}$ in the French series [1].

Procedural success and risk of death may depend on lesion characteristics [19]. French authors avoided tortuous lesions and chronic total occlusions (CTOs). CTOs are numerically predominant lesions in European patients, presumably purporting haemodynamic improvements when successfully managed, as whole lobes may be revascularised. While general recommendations caution against intervention of complex occlusions in the pulmonary arteries, particularly large branches and lobes, procedural skills and equipment in the future will have to include those lesions in the feasibility expectations of BPA. Currently available data suggest that angiographic type of treated lesion shows no correlation with the occurrence of lung injury, but multivariate analysis revealed that BPA-related vascular injury was the only independent factor associated with lung injury [20]. This may be related to current BPA treatment rules avoiding CTOs. CTO percutaneous coronary intervention generally requires more procedural resources and carries higher risk for complications than percutaneous coronary intervention of non-CTO vessels [21], and one may predict that this will be the same for BPA.

Finally, other factors may contribute to the differences observed in the procedural outcomes. Recently, a study comparing the vascular phenotypes of European with Japanese CTEPH patients on the basis of an analysis of surgical thromboendarterectomy specimens and corresponding plasmas, demonstrated that European CTEPH clots are larger, contain more red thrombus, and patients display a "metabolic syndrome"-like and more inflammatory thrombotic phenotype that may be accounted for by genetics, lifestyle or environmental interactions, and may be a determinant of differential treatment outcomes [22].

Taken together, current practice in treating CTEPH still varies between Europe and Asia. While in the present study roughly $60 \%$ of CTEPH patients were receiving medical treatments, Japanese physicians use less medical treatment support, with approximately half of patients on medical therapy stopping those treatments after BPA in the most recent multicentre registry [3]. Medical treatments could have led to better haemodynamics in European patients, but did not, thus emphasising other factors as mentioned above. The concept that European CTEPH harbours more secondary vascular disease in the pre-capillary compartment is hypothetical.

It took 15 years to develop and fine-tune BPA in Japan; therefore, an optimistic view is justified, and in upcoming years we expect even more excellent results than the ones shown here by French CTEPH experts in a European population.

Support statement: This work was supported by the Austrian Science Foundation F54 (to I.M. Lang).

Conflict of interest: I.M. Lang reports grants and personal fees from Actelion, Medtronic, Ferrer, Mochida and AOPOrphan Pharma, outside the submitted work. H. Matsubara reports personal fees from Actelion, AOP Orphan Pharmaceuticals AG, Bayer Yakuhin, Ltd, GlaxoSmithKline, Pfizer Japan, Inc., United Therapeutics, Nippon Shinyaku, Co., Ltd and Kaneka Medix Corporation, during the conduct of the study.

\section{References}

1 Brenot $\mathrm{P}$, Jaïs $\mathrm{X}$, Taniguchi $\mathrm{Y}$, et al. French experience of balloon pulmonary angioplasty for chronic thromboembolic pulmonary hypertension. Eur Respir J 2019; 53: 1802095.

2 Galie N, Humbert M, Vachiery J-L, et al. 2015 ESC/ERS Guidelines for the diagnosis and treatment of pulmonary hypertension. The Joint Task Force for the Diagnosis and Treatment of Pulmonary Hypertension of the European Society of Cardiology (ESC) and the European Respiratory Society (ERS). Eur Respir J 2015; 46: 903-975.

3 Ogawa A, Satoh T, Fukuda T, et al. Balloon pulmonary angioplasty for chronic thromboembolic pulmonary hypertension: results of a multicenter registry. Circ Cardiovasc Qual Outcomes 2017; 10: e004029.

4 Inami $\mathrm{T}$, Kataoka $\mathrm{M}$, Yanagisawa $\mathrm{R}$, et al. Long-term outcomes after percutaneous transluminal pulmonary angioplasty for chronic thromboembolic pulmonary hypertension. Circulation 2016; 134: 2030-2032.

5 Simonneau G, Montani D, Celermajer DS, et al. Haemodynamic definitions and updated clinical classification of pulmonary hypertension. Eur Respir J 2019; 53: 1801913.

6 Olsson KM, Wiedenroth CB, Kamp JC, et al. Balloon pulmonary angioplasty for inoperable patients with chronic thromboembolic pulmonary hypertension: the initial German experience. Eur Respir J 2017; 49: 1602409.

7 Andreassen AK, Ragnarsson A, Gude E, et al. Balloon pulmonary angioplasty in patients with inoperable chronic thromboembolic pulmonary hypertension. Heart 2013; 99: 1415-1420.

8 Voorburg JA, Cats VM, Buis B, et al. Balloon angioplasty in the treatment of pulmonary hypertension caused by pulmonary embolism. Chest 1988; 94: 1249-1253.

9 Feinstein JA, Goldhaber SZ, Lock JE, et al. Balloon pulmonary angioplasty for treatment of chronic thromboembolic pulmonary hypertension. Circulation 2001; 103: 10-13.

10 Mizoguchi $\mathrm{H}$, Ogawa A, Munemasa M, et al. Refined balloon pulmonary angioplasty for inoperable patients with chronic thromboembolic pulmonary hypertension. Circ Cardiovasc Interv 2012; 5: 748-755.

11 Biole C, Huczek Z, Nunez-Gil I, et al. Daily risk of adverse outcomes in patients undergoing complex lesions revascularization: a subgroup analysis from the RAIN-CARDIOGROUP VII study (veRy thin stents for patients 
with left mAIn or bifurcatioN in real life). Int J Cardiol 2019; in press [https://doi.org/10.1016/j.ijcard.2019. 03.038].

12 Tromeur C, Jais X, Mercier O, et al. Factors predicting outcome after pulmonary endarterectomy. PLoS ONE 2018; 13: e0198198.

13 Inohara $\mathrm{T}$, Kawakami $\mathrm{T}$, Kataoka $\mathrm{M}$, et al. Lesion morphological classification by OCT to predict therapeutic efficacy after balloon pulmonary angioplasty in CTEPH. Int J Cardiol 2015; 197: 23-25.

14 Fanaroff AC, Zakroysky P, Dai D, et al. Outcomes of PCI in relation to procedural characteristics and operator volumes in the United States. J Am Coll Cardiol 2017; 69: 2913-2924.

15 Inami $\mathrm{T}$, Kataoka $\mathrm{M}$, Shimura $\mathrm{N}$, et al. Pressure-wire-guided percutaneous transluminal pulmonary angioplasty: a breakthrough in catheter-interventional therapy for chronic thromboembolic pulmonary hypertension. JACC Cardiovasc Interv 2014; 7: 1297-1306.

16 Riedel M, Stanek V, Widimsky J, et al. Longterm follow-up of patients with pulmonary thromboembolism. Late prognosis and evolution of hemodynamic and respiratory data. Chest 1982; 81: 151-158.

17 Maron BA, Hess E, Maddox TM, et al. Association of borderline pulmonary hypertension with mortality and hospitalization in a large patient cohort: insights from the Veterans Affairs Clinical Assessment, Reporting, and Tracking Program. Circulation 2016; 133: 1240-1248.

18 Jamieson SW, Kapelanski DP, Sakakibara N, et al. Pulmonary endarterectomy: experience and lessons learned in 1500 cases. Ann Thorac Surg 2003; 76: 1457-1462.

19 Kawakami T, Ogawa A, Miyaji K, et al. Novel angiographic classification of each vascular lesion in chronic thromboembolic pulmonary hypertension based on selective angiogram and results of balloon pulmonary angioplasty. Circ Cardiovasc Interv 2016; 9: e003318.

20 Ejiri K, Ogawa A, Fujii S, et al. Vascular injury is a major cause of lung injury after balloon pulmonary angioplasty in patients with chronic thromboembolic pulmonary hypertension. Circ Cardiovasc Interv 2018; 11: e005884.

21 Salisbury AC, Karmpaliotis D, Grantham JA, et al. In-hospital costs and costs of complications of chronic total occlusion angioplasty: insights from the OPEN-CTO Registry. JACC Cardiovasc Interv 2019; 12: 323-331.

22 Chausheva S, Naito A, Ogawa A, et al. Chronic thromboembolic pulmonary hypertension in Austria and Japan. J Thoracic Cardiovasc Surg 2019; in press [https://doi.org/10.1016/j.jtcvs.2019.01.019]. 